\title{
Aanbidding en PREDiking in Missionale GeMEENTES - HOMILETIES- LITURGIESE BESKOUINGE VAN MISSIONÊRE GEMEENTEBEDIENING
}

Author:

Guillaume H. Smit ${ }^{1,2}$

\section{Affiliations:}

${ }^{1}$ Buro vir Voortgesette

Teologiese Onderrig

(Buvton), Fakulteit

Teologie, Universiteit

Stellenbosch, Suid-Afrika

${ }^{2}$ Departement Praktiese

Teologie, Universiteit van

Pretoria, Suid-Afrika

\section{Correspondence to:}

Guillaume Smit

email:

ghsmit@telkomsa.net

Postal address:

Posbus 195, Brackenfell

7561, Suid-Afrika

\section{Keywords:}

missionale gemeente;

ekklesiologie; homiletiek;

liturgie; bediening

Dates:

Received: 08 July 2009

Accepted: 22 Dec. 2009

Published: 14 May 2010

How to cite this article:

Smit, G.H., 2010,

'Aanbidding en prediking in missionale gemeentes

- homileties-liturgiese beskouinge van missionêre gemeentebediening', HTS Teologiese Studies/ Theological Studies 66(1), Art. \#313, 6 pages. DOI: 10.4102/hts.v66i1.313

This article is available at:

http:/ /www.hts.org.za

\section{INLEIDING}

\section{Die omskepping van tradisionele, instandhoudingsgerigte eredienste tot missionale aanbiddingsgeleenthede}

\section{Die tsunami van verandering}

Reeds so lank gelede soos 1991 skryf Loren Mead (1991:84): 'A new church is being born around us. That is my thesis.' Hy word hierin voorgegaan deur Callahan (1990:13), wat verklaar dat die dae van 'n 'gekerkte kultuur' verby is, want die era van die sendingveld het aangebreek. 'Gekerkte kultuur' veronderstel die tydperk tussen $313 \mathrm{nC}$ en die middel van die 20ste eeu toe die kerk 'n sentrale en oorheersende rol in die Westerse samelewing gespeel het (Gibbs \& Bolger 2005:17). In die 20 jaar sedert hierdie amper profetiese opmerkings het die samelewing inderdaad ingrypend verander, is die kerklike omgewing drasties omvorm, en is die teologie by ' $n$ paradigmaskuif betrek wat al as ' $n$ 'tsunami van verandering' beskryf is (Niemandt 2007:9). Ons leef tans in 'n werklikheid wat ten beste as 'n oorgangsera, ' $\mathrm{n}$ 'ecotone between the modern era and a time we cannot yet define', beskryf kan word (Sweet, McLaren \& Haselmayer 2003:18). Hoewel dié era haas onomskryfbaar is, is ' $n$ verskeidenheid skrywers en navorsers dit darem eens dat elkeen wat probeer kleinkry wat dit beteken om postmodern te wees, deurlopend bewus raak van die relatiwiteit of voorlopigheid van alle menslike denke en dade (Allen, Blaisdell \& Johnston 1997:10).

\section{Uitdagings in bedieningspraxis}

Die paradigmaskuif wat besig is om plaas te vind lei tot nuwe uitdagings in kerklike bedieningspraktyke. Vir die doeleindes van dié argument verwys bedieningspraktyke(bedieningspraxis) na die handelinge van individue en groepe in die samelewing, sowel binne as buite die kerk, wat deur die Christelike geloof geïnspireer wil word, en hulle só laat rig op die heil van die mens en die wêreld (Heitink 1993:148). Bedieningspraxis verwys dus na die werksaamhede van gemeentes ín en déúr gemeentelede om die heil van Christus sigbaar in hulle spesifieke gemeenskappe uit te leef (Smit 2008b:162), en handel dus oor die geïntegreerde funksionering van die hele gemeente (Smit 1997:39).

Die uitwerking van die teologiese paradigmaskuif op die kerk se bedieningspraxis is voorheen al as 'n 'ekklesiologiese metanoia', met ander woorde 'n soort bekering van die kerkleer, beskryf (Smit 2008a:110). Die kern van hierdie bekering is die groeiende konsensus dat die kerk se identiteit dié is van medewerker aan God se sending aan die wêreld (Bosch 1991:389-393; Burger 1999:78-90; Güder 2000:47-48; Nel 1994:28-33); dat die kerk as't ware opnuut sendeling moet word. Die begrip wat tans gebruik word om hierdie groeiende insig te verwoord is 'missionale kerk'. Hirsch omskryf 'n missionale gemeente soos volg:

[A] community of God's people that defines itself, and organizes its life around, its real purpose of being an agent of God's mission to the world. In other words, the church's true and authentic organizing principle is mission. When the church is in mission, it is the true church[.]

(Hirsch 2006:82)

Volgens Niemandt (2007:62) het 'n missionale gemeente die volgende geloofsgewoontes:

- ' 'n Vereenselwiging met die lewe van Jesus Christus, en 'n sterk fokus op die koninkryk van God.

- Die doelbewuste omskepping van die sekulêre sfeer deur die dualisme tussen geestelike en wêreldse sake af te lê.

- 'n Sterk klem op die kerk as geloofsgemeenskap.

- Openheid teenoor vreemdelinge.

- Vrygewige diensbaarheid sonder om iets terug te verwag.

- Funksionering deur die deelname van gemeentelede.

- 'n Klem op kreatiwiteit.

- Leierskap wat deur netwerke eerder as hiërargiese strukture ontwikkel.

- Die kontemporêre aanbieding van antieke godsdienstige waarhede.
Licensee: OpenJournals Publishing. This work is licensed under the Creative Commons Attribution License. 
TABEL 1

Bedieningsmerkers in die paradigmaskuif na missionale gemeentebediening

\begin{tabular}{|c|c|c|c|}
\hline & Identiteit & Groeie & Diens \\
\hline \multicolumn{4}{|l|}{ Individu } \\
\hline Godsbeelding & $\begin{array}{l}\text { 'n Verbonds-gemeenskap wat deur die Vader } \\
\text { geroep is. }\end{array}$ & $\begin{array}{l}\text { 'n Nuwe lewe deur die verlossingswerk van Jesus } \\
\text { Christus. }\end{array}$ & $\begin{array}{l}\text { Bemagtig deur die dinamiese werking van die } \\
\text { Heilige Gees. }\end{array}$ \\
\hline \multicolumn{4}{|l|}{ Groep } \\
\hline Verhoudingsgestaltes & $\begin{array}{l}\text { 'n Lewe van dankbaarheid voor die aangesig } \\
\text { van God. }\end{array}$ & Leierskap as gawe van die liggaam van Christus. & Die kerk as 'n huisgesin. \\
\hline \multicolumn{4}{|l|}{ Bediening } \\
\hline Missionaal & $\begin{array}{l}\text { Leitourgia (Aanbidding gerig op die eer van die } \\
\text { Drie-enige God). }\end{array}$ & $\begin{array}{l}\text { Koinonia (Gawegedrewe bediening gerig op die } \\
\text { opbou van die gemeente). }\end{array}$ & $\begin{array}{l}\text { Marturia (Lewensgetuienis gerig op die uitbrei- } \\
\text { ding van God se nuwe wêreld). }\end{array}$ \\
\hline
\end{tabular}

\section{'n Missionale paradigmaskuif in evangelieoordrag}

Die Christelike geloof behels tipies wederkerigheid, kommunikasie en handelinge, en die geloofsverhouding word kenmerkend 'n dinamiese krag wat mense tot optrede aanspoor (Pieterse 2008:140). Juis as gevolg van hierdie wederkerigheid is ' $n$ verwantskapsbenadering tot geloof, kerk en Skrif nodig, omdat Christene tog in ' $n$ verhouding met die God van die Bybel leef (McKnight 2008:84). Die wisselwerking tussen die besig-wees van God in hierdie wêreld, en die besig-wees van die geloofsgemeenskap sáám met God, veroorsaak 'n eiesoortige paradigmaskuif in evangelieoordrag in teologiese teorie, sowel as in die bedieningspraxis wat die onderhawige teorieë ten uitvoer moet bring. Dié paradigmaskuif kan aan die hand van 'n aantal hermeneuties-kommunikatiewe bedieningsmerkers beskryf word. Volledigheidshalwe word hierdie merkers, wat voorheen as ' $n$ teologiese teorie vir missionêre gemeentebediening gedien het (Smit 2008b:167-170), skematies weergegee in tabel 1.

\section{Prediking as missionale ekklesiologiese uitdaging} Die voorgaande skema sluit aan by Long (1989:11) se opmerking dat aanbiddingsleiers, ook predikers, hulle én hul leierskapsrolle in verhouding tot die hele geloofsgemeenskap, sowel as die sekulêre gemeenskap waarin die gemeente funksioneer, moet verstaan. Veral op hierdie openbare gestaltes van die geloofsgemeenskap - die bediening van die erediens en Woordverkondiging - het die paradigmaskuif na missionale gemeentebediening die grootste impak. Sweet (1999:215) wys daarop dat postmoderne mense nie meer kerk toe gaan omdat hulle glo nie, maar omdat hulle op soek is na 'n belewing van God se teenwoordigheid. Hy noem hulle 'try-before-you-buy postmoderns' - juis ' $n$ beklemtoning van die missionale aard van die geloofsgemeenskap se openbare aangesig.

Hoewel nie alle lidmate noodwendig postmoderne verbruikers is nie, koester almal die verwagting dat hulle God deur die erediens sal 'ontmoet' - hetsy deur kragdadige prediking met ' $n$ formele liturgie (premodern), praktiese verkondiging met goed afgeronde voorsang (modern), of vertellende bekendmaking ('narratiewe proklamasie') met passievolle lofprysing en aanbidding (postmodern) (Smit 2008a:108-110). Per slot van rekening is die erediens ten diepste God se saak, en kom ' $n$ gemeente in die erediens byeen om hulle in die groot ontferming van God te baai en te verlustig (Müller 1990:1).

\section{'n Missionale praxis vir die erediens?}

Die merkers hier bo wat op missionêre bediening dui, kan tot ' $\mathrm{n}$ missionale bedieningspraxis uitgebou word, wat in die gereformeerde tradisie meewerk tot evangelieoordrag deur getuienis in 'n toenemend post-Christelike verband (Smit 2009). Hoewel daar geredeneer kan word dat die erediens nie die begin en die einde van ' $n$ gemeente se openbare byeenkomste uitmaak nie, en dat ' $n$ mens moet waak teen die verheffing van die erediens tot die enigste openbare aangesig van 'n gemeente, is die uitgangspunt, soos sowel Barnard (1981:3) as Müller (1990:3) dit verwoord, eenvoudig dat die erediens deur die eeue ' $\mathrm{n}$ kernplek in die kerk ingeneem het, en steeds inneem.
Hierdie veronderstelling is reeds so vroeg as in die gemeente in Jerusalem sigbaar, waar die gemeentelede, naas die byeenkomste aan huis, weens hulle toewyding aan die leer van die apostels ook daagliks in die tempel bymekaargekom het (Hand 2:42-47) Dingemans (1991b:44) verduidelik dat die Sondagerediens ' $n$ unieke gestalte is van die Christelike lewe, waarin die liturgiese ontmoeting met die Here en met mekaar ' $n$ kernplek het. In wat hy die belangrikste misverstand oor die eie aard van gereformeerde eredienste noem, onderstreep Smit (2009:96-98) boonop dat die erediens oor ' $n$ eie aard beskik (Smit 2009:88) -'die gereformeerde erediens bestaan uit' $n$ sekere aantal aspekte, elemente, oomblikke, praktyke of liturgiese handelinge'; dat daar ' $n$ bepaalde karakter onder eredienshandelinge verborge lê, en dat dit belangriker is om na die erediens te kyk op grond van die boodskap wat dit uitdra, die uitwerking waarna dit streef, die invloed wat dit uitoefen, die langtermyngevolge wat dit het, die stemming wat dit skep, die assosiasies wat dit meebring, en die gevoel wat dit wek. Müller (2008:60) het dus gelyk dat die kerk se missionale karakter duidelik in elke aspek van die erediensliturgie na vore moet kom: Die sendingsopdrag en aanbidding is immers dermate ineengevleg dat gemeenskaplike aanbidding (corporate worship) - as ruimte waar die belewing van God se lewende aanwesigheid gevier word (Smit 2009:99) noodsaaklik is vir enige missionale ekklesiologie.

\section{Doel van die ondersoek}

Derhalwe is die doel van hierdie ondersoek die ontwikkeling van ' $n$ bedieningspraxis vir missionale erediensbediening teen die agtergrond van die gereformeerde teologiese tradisie, en wel aan die hand van 'n gevallestudie.

\section{ENKELE TEOLOGIESE PARAMETERS VIR MISSIONALE EREDIENSBEDIENING}

\section{Eredienskommunikasie as metaforiese kommunikasie}

'n Ondersoek na ' $n$ bedieningspraxis vir missionale eredienste vereis eerstens dat enkele teologiese parameters neergelê word. Die erediens is een van die plekke in die gemeente waar geloofsvorming plaasvind, en is waarskynlik ook die hoofplek van geestelike vorming. Dit is die ruimte waar gemeentelede God merendeels gesamentlik aanbid, en sy teenwoordigheid as werklikheid vier. Dit is ook die missionêre omgewing van waar die bediening van die gemeente gerig en uitgestuur word.

Volgens Dingemans (1991a:118) bestaan geloof uit gemeenskaplike ervarings, wat deur vieringe, prediking, gebed en allerlei aktiwiteite vertolk, oorgelewer en lewend gehou word. In hierdie omskrywing maak hy heelwat ophef van die gemeenskaplike aard van die gemeente, en stel hy ook 'n hoë prys op die gemeente se amptelike byeenkomste. Tog is die erediens nie bloot ' $n$ leringsruimte nie. Die veranderende samelewing maak so ' $\mathrm{n}$ benadering in ieder geval toenemend onmoontlik. Vos (2003:179) wys daarop dat die taal van die erediens - die liturgie - in wese metafories is, wat op sy beurt tot geestelike vorming bydra, wat dan in die openbare domein tot uiting kan kom. Sonder ' $\mathrm{n}$ waardering vir die metaforiese, sal ons nie óór en mét die Onsienbare God kan praat nie (Vos 2003:180). 


\section{Eredienskommunikasie in 'n mediagedrewe kultuur}

Babin (1991:54-55) voer aan dat die taal van die media die belangrikste bevorderlike element vir ' $n$ nuwe manier van godsdienstige vorming is. Dit het veral te make met die 'imprint which media technologies leave on our nervous system'. Dit gaan dus nie meer oor wát mense verstaan nie, maar hóé hulle verstaan. Die opkoms van multimediategnologie het mense se ervaringswêreld permanent van linkerbreingerigte (logiese) begrip na regterbreingerigte (intuïtiewe) begrip verskuif (Miller 2004:65).

Hierdie verskuiwing noop Sweet (1999:215-222) om die missionale uitdaging vir geloofskommunikasie deur die akroniem 'EPIC' te verwoord: $\mathrm{E}=$ experiential (ervaringsgegrond); $\mathrm{P}=$ participatory (deelnemend); I = interactive (interaktief); en $\mathrm{C}=$ communal (gemeenskaplik).

\section{Ervaringsgegrond}

In plaas van rasionele-logikaberedenerings van die evangelie, moet die kerk nou betekenisvolle geloofservarings aan kerkgangers bied (Sweet 1999:215). Daarom is 'die goeie nuus' nie ' $\mathrm{n}$ stel waarhede wat bewys moet word voor dit geglo kan word nie, maar vind die uitnodiging tot dissipelskap deur gevoel, musiek en energie plaas. Eweneens beteken prediking nie soseer om gevolgtrekkings te maak nie, maar eerder om moontlikhede oop te breek, en mense te nooi om deel te word van God se volk. Wepener (2009:13) omskryf die verband tussen evangelieverkondiging en mensevieringe in die teenwoordigheid van God soos volg: 'Liturgy . . . strives to develop the celebration/ doksa of the congregation which finds expression in worship and celebration so that the gospel can be effectively communicated.' In dié verband sê Dingemans (1991a:118) ook tereg dat individuele gemeentelede geloof op hul eie manier wil beleef.

\section{Deelnemend}

Volgens Sweet (1999:216) is kommunikasie nie daarop gemik om 'n boodskap oor te dra nie, maar 'to make common to many, to evoke a common experience, to participate. True communication and participation are more synonymous than we ever imagined'. Hierdie oorgang na ' $n$ deelnamekultuur noodsaak die skep van ' $n$ leeromgewing in kerke wat mense toelaat om bedieninge te ondersoek en vir hulself toe te eien. Ook Pieterse (2008:148) sê: '[L]idmate wil betrokke wees en deelneem aan die erediens.' Hy bepleit derhalwe gemeentelede se groter deelname aan die erediens (Pieterse 2008:149), met 'n aanverwante uitwerking op hulle deelname aan die prediking.

\section{Interaktief}

Volgens Sweet (1999:218) stimuleer die elektroniese kultuur aksie en interaksie. Volgens hom slaag 'n doeltreffende gemeente daarin om 'n interaktiewe medium tussen twee wêrelde te wees (Sweet 1999:220). Hierdie verskuiwing na interaksie bring sinvolle alternatiewe mee vir groter deelname aan die liturgiese gebeure gedurende die erediens. In die verband van die liturgiese gebeure word mense immers genoop om nuut te dink oor die huidige werklikheid én oor hulle identiteit ín hierdie werklikheid, omdat God sy aangesig na hierdie werklikheid gedraai het (Cilliers 2008:15). Dit skep geleenthede vir groter interaksie - die waarde van die Christus-werklikheid word juis in hierdie aardse werklikheid gevier en voorgestel deur interaktiewe rituele en simbole waarin gelowiges se identiteit tot uiting kan kom.

\section{Gemeenskaplik}

Te midde van 'n leëgemeenskapskultuur is dit die kerk se taak om haar mense van 'n morele kode te voorsien; 'n visie van die dinge wat die lewe waarde gee; 'n gevoel van inburgering in ' $n$ gemeenskap waartoe mense ' $n$ waardevolle bydrae kan lewer (Sweet 1999:221). Vir Bilezikian (1997:65) verg die vestiging van 'n geloofwaardige geloofsgemeenskap deeglike besinning, organisasie, koördinering en samewerking. Hy versamel dit alles onder die woord 'bediening', en beklemtoon dat dié term nie op die werk van die predikant slaan nie, maar op die lede van die geloofsgemeenskap wat op betekenisvolle wyse betrokke is in die opbou van die gemeente.

\section{'N VERHAAL VAN MISSIONALE OMSKEPPING VAN DIE EREDIENS}

\section{Die storie van 'n gemeente}

Die NG Kerk Brackenfell-Wes is 'n tipiese voorstedelike gemeente in Kaapstad, met ongeveer 2500 lidmate. ${ }^{1}$ Die gemeente het haar 25ste bestaansjaar in 2009 gevier. In dié kwarteeu het die gemeente Brackenfell-Wes ' $n$ aantal uitdagings die hoof gebied, waaronder die internasionaal berugte kerktoringdebakel, 'n gemeenteskeuring kort daarna, en die egskeiding van een van die predikante in diens van die gemeente. Die bedieningstyl in die gemeente was lank tradisioneel gereformeerd, met enkele vernuwende tendense, waarvan die vernaamste die inwerkingstelling van die Paidion-Kinderbedieningsmodel in 2003 was.

Pogings om ' $n$ meer informele aanbiddingstyl in die erediens te vestig het op interne spanning uitgeloop, hoofsaaklik oor die afwisseling van die orrel met 'n begeleidingsgroep al om die ander week, en die sing van Engelse liedere.

In 2004 is die senior kategese met 'n kleingroepbedieningsmodel en ' $n$ gepaardgaande eksperimentele jeugdiens vervang. Die kerkraad het beginselgoedkeuring verleen vir die diversifisering van eredienste, met ' $n$ klassieke (orrelbegeleide) erediens om 08:00, 'n gesinsgerigte (sanggroepbegeleide) erediens om 09:30, en 'n tienerdiens om 17:15 naas die normale aanddiens om 19:00. Die gemeente se fisiese geriewe was nie geskik vir 'n 'dubbeldoorbenadering' - met die klassieke en gesinsgerigte eredienste op dieselfde tyd maar in verskillende lokale - nie. Die kinderkerkdienste het tydens die 09:30-erediens plaasgevind. Die kerkraad sou hierdie besluit ná 'n jaar herbeoordeel.

Aan die einde van 2005 besluit die kerkraad om die dubbele oggenddienste te behou. Beginselgoedkeuring word ook verleen om die 17:15-tienerdiens na 18:30 te verskuif, sodat naskoolse jongmense ook die diens kan bywoon. Die gewone aanddiens het steeds om 19:00 plaasgevind, maar is na een van die groter kinderkerklokale verskuif, aangesien die tienerdiens meer mense as die gewone diens lok.

Aan die einde van 2006 besluit die kerk om albei aanddienste om 18:30 te hou sodat gesinslede wat saam kerk toe kom, kan kies watter diens hulle wil bywoon. Terselfdertyd is besluit dat die meer tradisionele erediens eerder ' $n$ luisterdiens sal wees, wat die beginsels van lectio divina, oftewel 'spirituele Skriflesing', insluit.

In hierdie tyd het die kerkraad ook met 'n strategiese, geloofsonderskeidende visievormingsproses afgeskop, waardeur gemeentelede die volgende roepingsverklaring ontwikkel het: 'Ons is die gemeente waar die evangelie sigbaar geleef word.' Die kerkraad het ook begin om 'n bestuurstelsel te ontwikkel wat uiting gee aan die gemeente se roeping om 'n missionêre kerk vir die gemeenskap te wees.

In 2008 is 'n reeks versoeningsdienste gehou as 'n uitvloeisel van die gemeente se deelname aan die 40 Dae van Doelgerigte Lewe-veldtog, Rick Warren se geesteskind. Die kerkraad het ook tot hierdie reeks toegestem na aanleiding van 'n voorlegging deur een van die gemeentelede oor die noodsaaklikheid van versoeningsprosesse wat die gemeente kan help om die

1.Inligting vir hierdie paragraaf kom uit die notules van die kerkraadsvergaderings van die NG Kerk Brackenfell-Wes van 2004 tot 2008. 
seerkryervarings van die verlede af te lê. Drie opeenvolgende Sondae is hieraan gewy. Gemeentelede is gevra om vriende, familielede en oudlidmate na hierdie geleenthede te nooi. Die eerste diens het oor die vertikale dimensie van versoening, naamlik versoening met God, gehandel. Die tweede erediens het die horisontale dimensie van versoening, dié tussen Christene onderling, aan die orde gestel. Op die derde Sondag is nagmaal gevier, en is die storie van die gemeente voorgehou. Elke hoofmoment het op verootmoediging voor God gekonsentreer terwyl daar ook baie aandag aan gebed gewy is. Ter afsluiting het die twee gemeenteleraars gemeentelede met nagmaal bedien.

In 2009 het die gemeente se gebedsbediening momentum opgebou, en is gemeentelede met gebedskontrakte - met ander woorde deelname aan voorbidding vir bepaalde temas vir ' $\mathrm{n}$ bepaalde tyd - by voorbidding betrek. Die kerkraad het ook met die nodige bearbeiding begin om ' $n$ gebedsmoment by eredienste in te bou waardeur gemeentelede gedurende die erediens by konkrete gebedsbediening kon inskakel. In 2009 is verskeie getuienisse aangehoor van die genadewerk van God deur gebedsverhoring, sowel as van mense wat hulle opnuut aan Christus toewy - iets wat voorheen nie juis algemeen in die gemeente voorgekom het nie.

\section{Missionale bedieningsverskeidenheid}

Die veranderende kultuur het die swaarste invloed op kerke wat vasgevang bly in die 'one-size-fits-all approach, typically proving that one-size-fits-nobody' (Barna 2005:63). Eie aan die 'dubbelringklimaat' van hierdie era, waar teenstrydige sake harmonieus naas mekaar kan bestaan (Sweet 1999:27), is dit moontlik om met bedieningsverskeidenheid in een gemeente te eksperimenteer ten einde ' $n$ uiteenlopende groep mense te bedien. In die NG Kerk Brackenfell-Wes word hierdie bedieningsverskeidenheid skematies saamgevat in tabel 2 .

\section{Tradisionele eredienste}

Hierdie tipe erediens maak voorsiening vir die godsdienstige verwysingsraamwerk van ouer en meer tradisioneel gereformeerde gelowiges. Die erediens volg die liturgiese lyn van ' $n$ tipiese gereformeerde diens, en behou die hoofmomente van die liturgiese beweging. Hoewel ' $n$ vaste liturgie nie gevolg word nie, is daar genoeg van die bekende om die diens ' $n$ veilige aanbiddingsomgewing te maak vir lidmate wat hierdie styl verkies. Die prediking is geloofsvormend, met die klem op die fasilitering van ' $n$ ontmoeting met Christus deur die Gees. Hoewel dié diens ' $n$ formeler styl het, is dit ' $n$ missionêre viering van God se teenwoordigheid. Dit bly ' $n$ uitdaging om in hierdie tradisionele opset interaksie en deelname deur gemeentelede te verhoog. Die rol van die prediker as liturg is stewig vasgelê, en lidmate sal dikwels net deelneem indien die prediker die inisiatief neem. Hierdie erediens is waarskynlik nie die beste meganisme om die gemeente se 'missionêre temperatuur' te verhoog nie. Indien dit egter deel uitmaak van 'n bedieningsmodel wat verskeidenheid in ag neem, kan 'n liturgiese aanslag met rituele en meer simboliek die teenwoordigheid van God sigbaarder vier.

\section{Gesinsdienste}

Hierdie soort erediens hou rekening met die godsdienstige verwysingsraamwerk van ' $n$ jonger generasie Christen. Hierdie mense kom tipies uit die era van die Jeugsangbundel, die doodsnikke van die Kerkjeugaksiebeweging, en die geboorte van jeugkleingroepe. Hulle verkies 'n dubbelringbenadering waar hulle kinders afsonderlik in ' $n$ kinderkerk bedien word. Die sangbegeleiding in die erediens moet verkieslik deur 'n lofprysingsgroep hanteer word. Die kerninstrumente vir begeleiding is kitare, ' $n$ klavier of klawerbord, en ' $n$ aantal voorsangers. Perkussie is ' $n$ opsionele toevoeging. Die predikingstyl is informeel, wat ook ' $\mathrm{n}$ informele atmosfeer help skep. Gemeentelede neem deel deur die kinderkerk te begelei, en in die voorsanggroep, die multimediaspan of die gasvryheidspan te dien. Die gemeente het met hierdie erediens doelbewus met verskillende geleenthede vir gebedsbediening begin eksperimenteer. Dit wissel van gebedsgeleenthede gedurende die erediens, 'n gebedskamer ná die diens, en getuienisgeleenthede en lofprysingsdienste met die klem op getuienis oor God se voorsiening.

\section{Opkomendegenerasiedienste}

Gedurende die 18:30-erediens van die NG Kerk Brackenfell-Wes word nuwe kommunikasietegnieke vrylik op die proef gestel. Aangesien die fokusgroep adolessente en jong volwassenes is, bied dié diens 'n groter geleentheid vir doelbewuste geloofsvorming. Die doel is dus om so prakties en aktueel moontlik te wees, sonder om in oppervlakkige teologie te verval. Sang gedurende hierdie erediens word deur 'n groep met hoofsaaklik kitaar- en perkussie-instrumente gelei. In die segment wat aan lofprysing en aanbidding afgestaan word, word gemeentelede aangemoedig om uiting te gee aan ' $\mathrm{n}$ oorhoofse fokus op God. Die prediking is doelbewus interaktief. Die prediker moet bereid wees om as deel van die boodskap met gemeentelede in gesprek te tree, deelname uit te lok en uit die vuis te dink. Die diens maak vrylik gebruik van multimediavideogrepe wat as boodskapdraers ingespan word. Etlike toneelstukke is ook al opgevoer. ' $\mathrm{n}$ 'Vra-die-dominee'erediens is ' $n$ gereelde instelling, waartydens diegene in die diens ' $n$ boodskap na ' $n$ selfoonnommer stuur - hetsy per SMS of deur die netwerkprogram Mxit - en dié vrae dan gedurende die diens beantwoord word. Die opkomendegenerasiediens bou lidmaatdeelname selfs verder uit deur betrokkenheid by die beplanning van die eredienste, deelname aan die toneelstukke, of samestelling van die videogrepe. Die geloofsgemeenskap word doelbewus as vriendekring hanteer, en die gemeentelede in verhoudingsnetwerke aan mekaar verbind. Die hoofdraer van hierdie verhoudingsnetwerke is kleingroepe en sosiale geleenthede.

\section{'VERSENDELINGSBAKENS' IN DIE GEVALLESTUDIE}

Dit sou riskant wees om uit 'n enkele gevallestudie algemene afleidings te probeer maak. Tog kan 'n mens aan die hand van Niemandt (2007:62) se beskrywing enkele bakens in hierdie gemeente se 'versendelingsproses' - hulle reis na missionale gemeentebediening - eien.

Dit val byvoorbeeld op dat die kerkraad algaande ernstiger geraak het om die gemeente se roeping in haar onmiddellike verband te heromskryf. Die tradisionele klem op behoudendheid het plek gemaak vir' $n$ vars klem op geloofsgemeenskap; in plaas van tradisie is bediening vooropgestel. Bedieningsvernuwing het egter nie ter wille van vernuwing plaasgevind nie, maar om mense met die evangelie van Jesus Christus te bereik. Hoewel

TABEL 2

Bedieningsverskeidenheid in die NG Kerk Brackenfell-Wes

\begin{tabular}{llll}
\hline Tradisioneel & Gesin & Opkomende generasie \\
\cline { 1 - 1 } Formele liturgie & Informele liturgie & Onsigbare liturgie \\
\hline Sang met klassieke begeleiding (orrel). & Sang met voorsanggroep. & $\begin{array}{l}\text { Sangbegeleiding weerspieël die kultuurbelewing van die opko- } \\
\text { mende teikengroep. }\end{array}$ \\
$\begin{array}{llll}\text { Praktykgerigte prediking wat fokus op die fasilitering van } \\
\text { n ontmoeting met God. }\end{array}$ & $\begin{array}{l}\text { Praktykgerigte prediking wat fokus op die fasilitering } \\
\text { van 'n ontmoeting met God. } \\
\text { Min simbole en rituele. }\end{array}$ & $\begin{array}{l}\text { Verkondiging in gesprekstrant, met interaktiewe deelname deur } \\
\text { gehoor. }\end{array}$ \\
\hline
\end{tabular}


die gemeente se bediening nie tot haar eredienste gereduseer kan word nie, is dit tog duidelik dat die erediens se kernplek in gemeentes uit die gereformeerde tradisie nie onderskat moet word nie. Die gemeente se getuienis vertel ook nie hoofsaaklik die verhaal van groei of finansies of oorsese sendelinge nie, maar eerder veranderde lewens, geestelike diepgang, en groter betrokkenheid by die nood van die gemeenskap. So is ' $n$ hulpskema, Projek Vonkelogies, van stapel gestuur vir mense wat finansieel swaarkry. Die maatstawwe waarvolgens hulp verleen is, is die bydrae wat hierdie mense tot die uitbreiding van die koninkryk kan lewer, en die feit dat die skema die hulpbehoewendes moet nader om hulle by te staan. Die projek sou aanvanklik ' $n$ jaar duur, maar is uiteindelik met nóg 'n jaar verleng om al die vrywillige bydraes en mense in nood te hanteer.

Hierbenewens is etlike alternatiewe bedieninge in die lewe geroep, soos ' $\mathrm{n}$ inreikspan wat met ' $\mathrm{n}$ bediening begin het om Jesus se liefde aan gemeentelede, verkieslik diegene wat randkerklik is, te betoon. Die bedoeling is om hulle by die geestelike familieopset van die gemeente te betrek, en om die verlossingsboodskap van Jesus op 'n aktuele, nuwe manier oor te dra. Die gebedsbediening wat reeds hier bo bespreek is, is ' $n$ tweede alternatiewe bediening wat die lig gesien het. Hierbenewens het die gemeente se kleingroepe vir volwasse lidmate beduidend uitgebrei - van drie aktiewe groepe in 2007, tot 15 in 2009.

Dit is insiggewend dat die grootste beweging om aan God se werk in die gemeentearea deel te neem plaasgevind het toe sy teenwoordigheid in die lewens van die gemeentelede sigbaar geword het. Albei predikante meld ' $n$ toename in gespesialiseerde pastorale werk aan, sowel as ' $n$ toename in vrywilligers wat hulle vir diens beskikbaar stel. Die prediking is doelbewus missionaal - met die klem op die viering van die teenwoordigheid van God, en die uitdaging aan gemeentelede om hulle roeping konkreet te begin uitleef. Een van die uitdagings wat die NG Kerk Brackenfell-Wes nog in die gesig staar, is die kultuursprong na Engelse eredienste om die instroming van nie-Afrikaanse lidmate in die gemeenskap as bedieningsveld te ontgin.

Ter sam vatting het die NG Kerk Brackenfell-Wes se versendelingsproses aan die hand van haar erediensvernuwing die volgende missionale winste getoon:

- $\quad$ 'n Sterker klem op die sigbaarmaking van Jesus Christus in die daaglikse lewens van haar gemeentelede.

- 'n Gebedsverdieping wat ten nouste met gemeentelede se alledaagse lewens verband hou, en dit by hulle geloofsverhouding integreer.

- Meer gemeentelede neem deel aan lewensvormende kleingroepe.

- Die sukses van Projek Vonkelogies, en die toename in lidmate in bedieningspanne, dui op ' $n$ verhoging in lidmate se diensbaarheid.

- Die wyse waarop die gemeente met haar eredienste omgaan, en die permanensie wat haar sangbediening in die gemeentekultuur verkry het, toon Brackenfell-Wes se kreatiewe ingesteldheid. Die klaarblyklike sukses van onder meer die versoeningsreeks toon voorts dat die Bybelse geloofswaarhede op 'n kontemporêre wyse aangebied kon word om gemeentelede se waardes te help vorm.

Ten spyte van hierdie missionale winste, bestaan daar steeds enkele struikelblokke op die gemeente se weg van versendeling. Hoewel die inreikspan doelbewus missionaal te werk gaan, is die gemeente nog te veel op 'haar eie mense' gerig - oftewel mense wat op haar lidmaatregister verskyn - eerder as om juis oop te wees vir enigeen in haar primêre bedieningsgebied. Hierbenewens sukkel die NG Kerk Brackenfell-Wes steeds om haar bestuurstelsels tot ' $\mathrm{n}$ lidmaatgedrewe bedieningspan te omvorm, alhoewel daar ' $n$ betekenisvolle toename in die diensbaarheid van lidmate blyk te wees,. Te veel van die tradisionele elemente het in die kerkraadstruktuur oorgebly. 'n Formele herstruktureringsproses is as kritiese prestasie-area gedefinieer met die verwagting dat dit deur die loop van die komende jare geïmplementeer sal word.

\section{GEVOLGTREKKING}

\section{Eredienste as wegspringblok vir 'n missionale bedieningsproses}

Die erediens ís nie die gemeente nie; die erediens is ' $n$ bediening van die gemeente. Die erediens is ' $n$ hoofbediening van die gemeente - 'n krag wat missionale omskepping kan teweeg bring. Deur die viering van die lewende God se inwonende teenwoordigheid in die lewens van gemeentelede, en hulle getuienis van aanbidding en verootmoediging, kan die erediens die kernmoment word vir plaaslike gemeentes om steeds hulle roeping in hierdie snelveranderende tyd te vervul. Geleenthede vir verdere navorsing is legio:

- Missionêre prediking wat nie in die 'soekerdiensmentaliteit' verval nie, maar ' $n$ navertelling is van die werk van God in die gemeenskap, moet indringend ontgin word.

- Die liturgie moet opnuut ondersoek word. Die erediens bestaan immers nie net uit lofsang en prediking nie, en in minder formele eredienste kan die Bybelse elemente wat ' $n$ ontmoeting met God fasiliteer, teologies misken word.

- Die plek van bedieningspanne, en hoe dit by die rol en funksie van die liturg geïntegreer moet word, verg besinning.

- Evangelieoordrag aan 'n toenemend post-Christelike kultuur moet opnuut bedink word.

- Die gemeente as geloofsfamilie, en die bedieninge wat nodig is om hierdie metafoor as bedieningspraxis te ontwikkel, moet in navorsing verreken word.

In die beweging van God se werk in die wêreld is die kerk die onvolmaakste aspek van sy plan. Tog is dit duidelik dat God vir Hom uit elke stam, volk en nasie ' $n$ volk saamgeroep het om sy lof te besing. In ' $n$ kultuur van ekstreme individualisme is dit goed om nuwe lense te vind waardeur hierdie geloofsgemeenskap kan kyk om getrou te bly aan haar roeping om navertellers te wees van God se magtige teenwoordigheid in sy skepping. In missionale gemeentes is die erediens ' $n$ onlosmaaklike kernbediening om gemeentelede tot koninkryksdiens en ' $n$ intiemer geloofsverhouding met Christus oor te haal. Dit is daarom gepas dat Martoia (2008:39-40) die laaste woord spreek:

People seem to be crying out for action. Action that demonstrates life change,action that embraces risk in standing for values that run counter to imperialism and consumerism, action that shows information being translated into softer, bigger, more compassionate hearts. Our culture is tired of empty propositions and parroted platitudes. People are looking for embodiment; a fullblown living into the life of difference making.

(Martoia 2008:39-40)

\section{LITERATUURVERWYINGS}

Allen, R.J., Blaisdell, B.S. \& Johnston, S.B., 1997, Theology for preaching: Authority, truth and knowledge of God in a postmodern ethos, Abingdon Press, Nashville.

Babin, P., 1991, The new era in religious communication, Fortress Press, Minneapolis.

Barna, G., 2005, Revolution: Finding vibrant faith beyond the walls of the sanctuary, Tyndale House Publishers, Carol Stream.

Barnard, A.C., 1981, Die Erediens [Worship], NG Kerk Boekhandel, Pretoria.

Bilezikian, G., 1997, Community 101: Reclaiming the local church as community of oneness, Zondervan Publishing House, Grand Rapids.

Bosch, D.J., 1991, Transforming Mission. Paradigm shifts in theology of mission, New York, Orbis.

Burger, C.W., 1999, Gemeentes in die kragveld van die Gees: Oor die unieke identiteit, taak en bediening van die kerk van Christus [Churches in the force-field of the Spirit: The unique identity, mission and ministry of the Church of Christ], Buvton, Stellenbosch. 
Callahan, K.L., 1990, Effective church leadership: Building on the twelve keys, Harper San Francisco, New York.

Cilliers, J., 2008, 'In die omtrek van die Gees: 'n Besinning oor die ruimtelikheid van liturgie [In the circumference of the Spirit: A reflection on the spatiality of liturgy]', Praktiese teologie in Suid-Afrika 23(2), 1-2.

Dingemans, G.D.J., 1991a, In de leerschool van het geloof: Mathetiek en vakdidactiek voor catechese en kerkelijk vormingswerk [In the school of faith: Teaching methodology didactics for catechesis and religious cultural training], tweede oplaag, Handboek Praktische Theologie, Kok, Kampen.

Dingemans, G.D.J., 1991b, Als hoorder onder de hoorders: Een hermeneutische homiletiek [As a listener in the audience: A hermeneutical homiletics], Handboek Praktische Theologie, Kok, Kampen.

Gibbs, E., \& Bolger, R.K., 2005, Emerging churches: creating Christian community in postmodern cultures, Baker Academic, Grand Rapids.

Güder, D.L., 2000, The continuing conversion of the church, Wm. B. Eerdmans, Grand Rapids.

Heitink, G., 1993, Praktische theologie [Practical Theology] Handboek Praktische Theologie, Kok, Kampen.

Hirsch, A., 2006, The forgotten ways: Reactivating the missional church, Brazos Press, Grand Rapids.

Long, T.G., 1989, The witness of preaching, Westminster John Knox Press, Louisville.

Martoia, R., 2008, Transformational architecture: Reshaping our lives as narrative, Zondervan Publishing House, Grand Rapids.

McKnight, S., 2008, The blue parakeet: Rethinking how you read the Bible, Zondervan Publishing House, Grand Rapids.

Mead, L.B., 1991, The once and future church: Reinventing the congregation for a new mission frontier, The Alban Institute, New York.

Miller, M.R., 2004, The millennium matrix: Reclaiming the past reframing the future of the church, JosseyBass, San Francisco.

Müller, B.A., 2008, 'A missional understanding of the church its ministry, especially with regards to its Christ centric liturgical orientation', Nederduitse Gereformeerde teologiese tydskrif 49(1\&2), 53-65.

Müller, J., 1990, Die Erediens as fees [Worship as celebraction], NG Kerk Boekhandel, Pretoria.

Nel, M., 1994, Gemeentebou [Church building], Orion, Halfweghuis.
Niemandt, N., 2007, Nuwe drome vir nuwe werklikhede: Geloofsgemeenskappe in pas met 'n postmoderne wêreld [New dreams to new realities: Faith communities consistent with a postmodern world], Lux Verbi.BM., Wellington.

Pieterse, H.J.C., 2008, 'Deelname van gemeentelede aan die prediking: ' $n$ Herbesinning [Participation of congregants at the preaching: A reconsideration]', Praktiese teologie in SuidAfrika 23(1), 139-154.

Smit, D.J., 2009, 'Ontdek die eie aard van die gereformeerde erediens [Exploring the nature of reformed worship]', in C. Wepener \& J. van der Merwe (reds.), Ontdekkings in die erediens, pp. 87-108, Lux Verbi.BM., Wellington.

Smit, G., 1997, 'Ekklesiologie en gemeentebou: 'n Praktiesteologiese studie [Ecclesiology and church: A practicaltheological study', D.D.-proefskrif, Departement Praktiese Teologie, Universiteit van Pretoria.

Smit, G., 2008a, 'Ekklesiologiese merkers vir missionêre gemeentebediening in 'n postmoderne wêreld [Ecclesiological markers for congregational missionary in a postmodern world]', Nederduitse Gereformeerde teologiese tydskrif 49(1\&2), 106-117.

Smit, G., 2008b, 'Die ontwikkeling van 'n strategiese gemeentelike ekklesiologie: Op pad na 'n missionerende bedieningspraxis [The development of a strategic congregational ecclesiology: Towards a missional ministry praxis]', Acta Theologica 2008(1), 161-175.

Smit, G., 2009, 'n Missionale alternatief vir huisbesoek? Hermeneutiese boustene vir ' $\mathrm{n}$ missionêre ekklesiologie [A missional alternative to pastoral visits? Hermeneutic building blocks for a missionary ecclesiology], Praktiese teologie in Suid-Afrika 24(1), 173-190.

Sweet, L., 1999, Soultsunami: Sink or swim in new millennium culture, Zondervan, Grand Rapids.

Sweet, L., McLaren, B.D. \& Haselmayer, J., 2003, A is for abductive: The language of the emerging church, Zondervan Publishing House, Grand Rapids.

Vos, C.J.A., 2003, 'Liturgical language as metaphorical language', Praktiese teologie in Suid-Afrika 18(2), 179-193.

Wepener, C., 2009, From fast to feast: A ritual-liturgical exploration of reconciliation in South African cultural contexts, Peeters, Leuven. 